OAI-PMH: http://www.indteca.com/ojs/index.php/Revista Scientific/oai

Artículo Original / Original Article

\title{
Discurso del Docente como Líder Transformacional
}

Autora: Karen Tatiana Quintero Gutiérrez Universidad Pedagógica Experimental Libertador, UPEL

tatica37@hotmail.com

Mérida, Venezuela

https://orcid.org/0000-0002-2426-4348

\section{Resumen}

El presente artículo pretende edificar un constructo teórico sobre el discurso del docente como líder transformacional y por ello persigue como propósitos conceptualizar el discurso docente como líder transformacional, analizar sus particulares, categorizar y describir sus elementos característicos. La investigación se realizó dentro del enfoque epistémico cualitativo, bajo el método hermenéutico, de tipo descriptivo y documental, haciendo uso de la abstracción crítica de la temática. Dentro de los hallazgos se desarrollaron constructos teóricos sobre el docente como líder transformacional, el discurso del docente como líder transformacional, sus particularidades y elementos característicos. La intencionalidad del artículo se basa en provocar reflexiones teóricas y acciones prácticas con la intención de vincular a los docentes con las nuevas teorías gerenciales, a fin de mejorar la praxis rutinaria en que se encuentra inmersa la educación.

Palabras clave: discurso; docente; liderazgo.

Cómo citar este artículo:

Quintero, K. (2019). Discurso del Docente como Líder Transformacional. Revista Scientific, 4(14), 228-248, e-ISSN: 2542-2987. Recuperado de: https://doi.org/10.29394/Scientific.issn.2542$\underline{2987.2019 .4 .14 .11 .228-248}$

Fecha de Recepción: 20-05-2019
Fecha de Aceptación:

09-08-2019
Fecha de Publicación:

05-11-2019 


\section{Teacher's Speech as Transformational Leader}

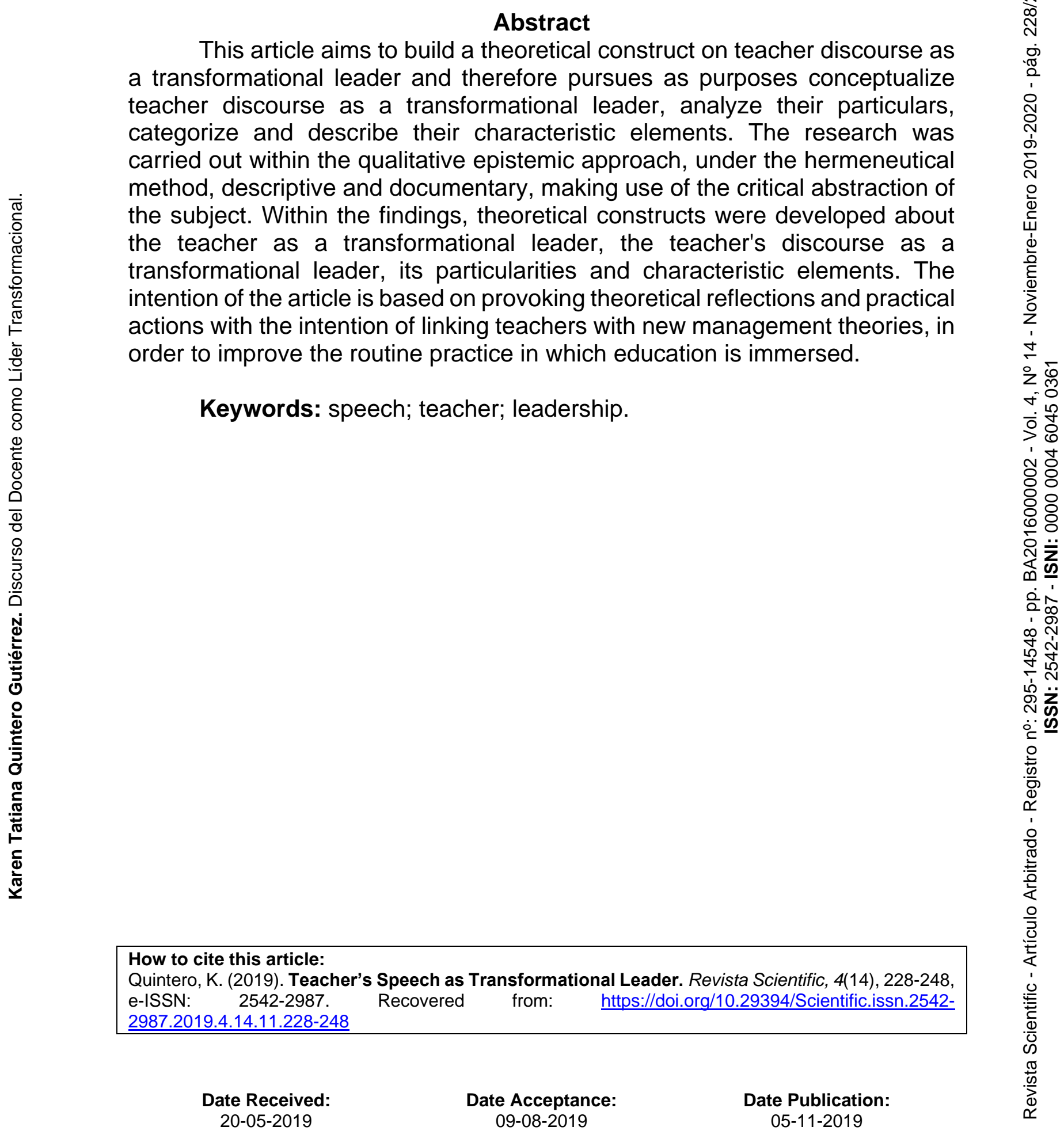




\section{Introducción}

La sociedad actual se encuentra sumergida en una vorágine de transformaciones sociales complejas que se incrementan a un ritmo apresurado y hacen imposible la renovación en todos sus ámbitos (políticos, económicos, sociales, entre otros), evidenciándose cierto rezago para solventar los problemas que le atañen y la educación no escapa de ello, tal y como lo plantea Morín (1999), cuando señala:

A este problema universal está enfrentada la educación del futuro porque hay una inadecuación cada vez más amplia, profunda y grave por un lado entre nuestros saberes desunidos, divididos, compartimentados y por el otro, realidades o problemas cada vez más polidisciplinarios, transversales, multidimensionales, transnacionales, globales, planetarios (pág. 15).

Esta complejidad social ha causado que los actores educativos, sobre todo los docentes, se enfrenten a nuevos escenarios ante los cuales no cuentan con las herramientas necesarias para afrontarlos, limitando su accionar, condicionando la praxis pedagógica y anclándose a modos de actuar que evaden la realidad contextual a la que se enfrentan diariamente.

Del mismo modo, el acontecer político-social que vive nuestro país, Venezuela, en los actuales momentos ha creado escenarios confusos y en el ámbito educativo las tribulaciones organizacionales se han hecho cada vez más evidente, exigiendo una renovación urgente en sus pilares gerenciales, de allí que se haga necesario implementar nuevas estrategias obligando a los actores del sistema educativo y específicamente a los docentes a salir del status quo en el cual permanecen.

Tal situación queda en certidumbre al evaluar la funcionalidad del sistema educativo y evidenciar como existen docentes que aún se encuentran anclados a discursos conductistas y tradicionales, convirtiéndose en simples transmisores de información, sin una visión prospectiva, entrópicos, apócrifos, 
indiferentes e insensibles, de aquellos que ven a los estudiantes como meros receptores.

Lo anteriormente expuesto, constituye una situación que ha de ser atendida, pues se ha observado como los docente exteriorizan la necesidad de un liderazgo competente, auténtico, innovador y transformador, que les permita transfigurar la praxis educativa, que lo convierta en un docente autocrático, proactivo, dinámico y capaz de influir psicológica e intelectualmente en sus estudiantes a través de un discurso resonante, carismático, motivador y transformador, idóneo para liderar el cambio en la práctica educativa.

En tal sentido, la labor pedagógica demanda el desarrollo de un liderazgo eficaz para promover el acto educativo, el cual, de acuerdo a los planteamientos de López (2019), corresponde: "con la vocación de servicio en el docente, en su naturaleza de ser, existir y coexistir con los demás en su labor de educar con amor al servicio superando los obstáculos o dificultades que surjan en su trayectoria" (pág. 246).

Así mismo, cabe destacar que toda práctica educativa se desarrolla a través de un proceso de interacción social, por ende la comunicación es un aspecto de gran relevancia en el quehacer educativo, de allí que la relación discursiva entre docente-estudiantes promueva el desarrollo de los procesos de enseñanza y aprendizaje, encausando la praxis educativa hacia el logro de los objetivos planteados y convirtiéndose en un factor influyente que anclado a las características de líder transformacional puede ser una herramienta importante para desmontar la práctica pedagógica conductista que se viene llevando a cabo en los recintos educativos.

Bajo estas consideraciones, surgieron las siguientes interrogantes respecto al discurso del docente como líder transformacional: ¿Cómo se ha instrumentado ese discurso en las aulas?; ¿Cuáles son los elementos que definen el discurso del docente como líder transformacional?; y en aras de dar 
respuesta a estos enigmas se plantearon como propósitos de investigación: (1) Conceptualizar el discurso docente como líder transformacional y (2) Determinar los elementos que caracterizan el discurso del docente como líder transformacional.

Finalmente, se determinó que el discurso del docente como líder transformacional se concibe como una acción comunicativa y herramienta pedagógica que permite regular el proceso de enseñanza y aprendizaje a través de los actos del habla: locucionario (lo que se dice), ilocucionario (la intencionalidad de lo que se dice) y percusionario (la reacción que provoca lo dicho). Del mismo modo se han podido determinar los elementos característicos del mismo entre los cuales se observa que es estimulante, motivacional, persuasivo, connotativo, performativo, asertivo, declarativo, orientador, proactivo y coherente.

\section{Conceptos y teorías}

\subsection{Discurso}

Al referirnos al discurso nos encontramos ante un término polisémico, sin embargo, existe una acepción general que lo considera como el uso del lenguaje y por ende una acción comunicativa que más allá de transmitir algún tipo de información, se emplea como una comunicación intersubjetiva que recae en intenciones de influir o convencer a los oyentes. Al respecto, Urra, Muñoz y Peña (2013): señalan que el discurso más "que el lenguaje oral o escrito, se refiere a cómo se usa el lenguaje en la realidad de los contextos sociales" (pág. 50).

Así pues, el discurso, además de establecer una relación con el contexto, instaura un razonamiento sobre la realidad social a través de la conversación espontánea en los encuentros cotidianos y promueve el aprendizaje. Esta relación dialéctica se ha instituido en la praxis docente como expresión y creación de significados sociales y organizacionales en el contexto 
educativo, promoviendo un acto pedagógico cargado de símbolos sociales y lenguaje que propician la transformación del conocimiento a través de los actos del habla.

\subsection{Discurso del Docente}

El discurso docente se concibe como el proceso comunicativo que regula la interacción docente-estudiantes a través de una secuencia coherente de enunciados que se adaptan a la situación contextual que se vive dentro del aula de clase y que persigue un objetivo intencional.

Al respecto, Diazgranados y Pastrana (2017a), señalan que el discurso docente, se concentra especialmente en: "producir en el estudiante una transformación, un cambio y una mejor adecuación o disposición para el aprendizaje" (pág. 27); en conclusión, se puede describir el discurso docente como el conjunto de mensajes orales a través de los cuales se manifiestan ideas, opiniones, sentimientos, que facilitan el proceso de enseñanzaaprendizaje y por ende tiene una connotación social.

Ante esta interpretación social que se le da al discurso docente, es importante que el profesor tome conciencia de la importancia que tiene y la influencia que ejerce sobre los estudiantes y su proceso pedagógico, de allí que se convierta en un líder que promueve la transformación del aprendizaje en las aulas de clases a través de su discurso y hacia el logro de objetivos comunes, pero con gran repercusión individual.

\subsection{Líder}

El líder es considerado como aquella persona que ejerce la autoridad para orientar y dirigir un grupo a fin de alcanzar metas $u$ objetivos que satisfagan las necesidades de una organización y alcanzar la efectividad de la misma a través del desarrollo continuo, generando el compromiso de los demás miembros de la organización a través de la motivación. Al respecto, 
Vázquez, Bernal y Liesa (2014): plantean que el líder, es un "orientador y guía que muestra el camino a seguir a sus colaboradores, proporcionándoles el apoyo y los recursos necesarios para que no se dispersen..." (pág. 82); en concordancia, la relación del líder se forja desde la confianza compartida con sus seguidores y siempre con el propósito de mejorar el desempeño organizacional y alcanzar la satisfacción personal.

Así mismo, un líder debe ser capaz de adecuarse a las situaciones que se le presente y en función de ello podrá asumir diferentes tipos de liderazgo, sin embargo, la praxis educativa vigente demanda patrones de liderazgo transformacional, a partir de los cuales los docentes como líderes sean capaces de motivar a los individuos a hacer más de lo que ellos mismos creen que pueden lograr, promoviendo cambios en los estudiantes y por ende generando la transformación en la práctica educativa.

\subsection{Líder Transformacional}

El líder transformacional es aquella persona que ejerce la autoridad más como un orientador que como un autócrata, pues, motiva y orienta a sus seguidores con el fin de alcanzar los objetivos propuestos a través de estrategias establecidas con rigurosidad y perspicacia, tal y como lo plantean Meza y Flores (2014a), cuando señalan, que el líder transformacional: "da sentido a lo que se hace e inspira a las personas a trascender sus propios intereses por un bien mayor" (pág. 103).

En correspondencia, el líder transformacional es aquel capaz de desarrollar preceptos organizacionales innovadores, adaptarse a situaciones de cambio y mantener una visión que favorezca las transformaciones necesarias, así mismo, se rige por una serie de cualidades, habilidades, destrezas y actitudes que definen sus características principales, las cuales de describen a continuación:

a). Carisma: atributo que permite establecer una vinculación emocional 
entre el líder y sus seguidores, permitiendo que se sientan motivados para el logro de los objetivos comunes, al respecto Meza y Flores (2014b): imprimen que el líder transformacional, tiene la "capacidad de entusiasmar, transmitir confianza, generar respeto, sentido de finalidad y orgullo por la tarea realizada" (pág. 104).

b). Proactividad: se refiere al comportamiento anticipado, orientado al cambio, es decir, que actúa ante una situación futura tomando el control y haciendo que las cosas sucedan en lugar de convenir ante la misma. El líder transformacional demuestra características de proactividad, de acuerdo a Meza y Flores (2014c), autores previamente citados: "cuando dirige su influencia a potenciar en el alumnado el interés hacia logro, la apertura continua al aprendizaje y les anima a trascender su interés individual con miras a un bien común" (pág. 103).

c). Creatividad: Representa la capacidad del líder para enfrentarse ante nuevos escenarios y actuar de forma estratégica e intencional para buscar la solución más adecuada. Para Meza y Flores (2014d): es la característica donde el líder "potencia los deseos de los seguidores, que logran metas y un desarrollo continuo, al mismo tiempo que promueve la mejora de los grupos y la organización" (pág. 104).

d). Sinergia e Interactividad: Se refiere a la relación de participación de los seguidores y atiende a la sincronía entre los miembros de la organización, en este sentido, Conger y Riggio (2006), añaden que para el líder transformacional: "los seguidores son personas de importancia, que son considerados en una relación de permanente interacción, con el fin de motivarlos e incentivarlos a lograr los objetivos propuestos" (pág. 2).

e). Ética y Coherencia: Se refleja cuando el líder mantiene la armonía entre el pensamiento, la palabra y la acción y actúa de forma correcta, adherido a los valores sociales y morales, en palabras de Riggio y Reichard (2008), el líder transformacional: se rige por un conjunto de valores claramente 
establecidos, los promueve, los defiende y los comparte como parte de su integridad (pág. 174).

f). Motivación: implica la capacidad del líder para estimular a los seguidores con el propósito de provocar el accionar para alcanzar los objetivos establecidos. Está relacionado con el nivel en que el líder articula una visión, haciéndola atractiva y vivificante.

Estas características son particularidades que identifican al líder transformacional en cualquier tipo de organización, incluso en el sistema educativo, donde se evidencia la urgencia de un cambio que obliga a los docentes a ejercer un liderazgo que le permita demostrar carisma para relacionarse con los estudiantes, creatividad en el desarrollo de los procesos académicos, motivación para la promoción del aprendizaje y coherencia entre el deber ser y su praxis cotidiana, demostrando así una disposición ética, que lo caracterice como un líder transformacional en el aula.

\subsection{Postulado Teórico. Teoría de los Actos del Habla}

Dentro de los postulados teóricos que sustentan la investigación encontramos la teoría de los actos del habla expuesta por Austin (1982) y Searle (2017): que en la esfera del discurso, conservan como pilares primordiales la intención y la acción del acto comunicativo, constituyendo uno de principios fundamentales de la pragmática, pues considera que hablar es hacer, que cada enunciado emitido repercute en la audiencia a través de un significado literal o proposicional y además posee una intencionalidad.

De acuerdo a esta teoría, los aspectos pragmáticos del discurso permiten al orador dar sentido al mismo tomando en cuenta el orden de las palabras, la entonación, el énfasis, el contexto, entre otros, y de este modo transmitir la fuerza comunicativa del discurso.

En tal sentido, esta teoría distingue tres actos del habla: (a) el acto 
locucionario que refiere a lo que se ha dicho; (b) el acto ilocucionario relacionado con la intención, el propósito o fin de la comunicación; y (c) el acto perlocutivo que hace énfasis en el efecto que el acto lingüístico produce. Por tanto, cada acto aporta una parte significativa al discurso, pero cada una mantiene relación con la otra y en suma permiten que el mismo mantenga un significado literal, una intencionalidad y una repercusión en el resto de las personas.

Desde esta perspectiva, el discurso docente como líder transformacional, se ancla en los postulados encontrados en la teoría del habla puesto que el mismo, debe atender a la intencionalidad motivacional, creativa y proactiva para lograr la transformación de la praxis educativa desde los aspectos epistemológicos que rigen el liderazgo transformacional, en este orden de ideas, la distinción entre lo que se dice, la intención con la cual se manifiesta y el efecto que causa, será trascendental, ya que sitúa el discurso docente (acto lingüístico) como parte vital para desarrollar sus características como líder y lograr una transformación en el proceso formativo de los estudiantes y en su manera de actuar.

\section{Metodología}

La investigación se realiza dentro del enfoque epistémico cualitativo, bajo el método hermenéutico, de tipo descriptivo y documental, haciendo uso de la abstracción crítica de la temática, por cuanto se analizaron algunos textos y publicaciones científicas que abordaron el discurso docente y el liderazgo transformacional.

Con relación a lo anterior, se consideraron el Discurso Docente y el Liderazgo Transformacional como unidades de análisis, describiendo sus principales características a través de la revisión bibliográfica documental. En este orden de ideas, Sabino (2006a), plantea que: "las investigaciones descriptivas se proponen conocer grupos homogéneos de fenómenos para 
establecer una descripción de sus características" (pág. 222). Del mismo modo, la investigación es del tipo documental por cuanto se apoya en el estudio de diversos documentos y publicaciones en las que sus autores presentan las bases teóricas de sus hallazgos, tal y como lo señala, Arias (2012): es "un proceso basado en la búsqueda, recuperación, análisis, crítica e interpretación de datos secundarios" (pág. 28).

Asimismo, el diseño de investigación se apoyó en la revisión de bibliografía pertinente al área, a través de la cual se seleccionaron distintas publicaciones científicas y artículos indexados, como punto de origen para la edificación de un constructo teórico emergente sobre el Discurso del Docente como Líder Transformacional, así como sus características. En concordancia, con Sabino (2006b), manifiesta que: "se fundamenta en la recopilación y análisis de contenidos documentales, los cuales se analizan mediante técnicas documentales" (pág. 30).

\section{Hallazgos}

\subsection{Docente como líder transformacional}

El docente en el ejercicio de sus funciones requiere desarrollar variadas características que son vitales para el desarrollo del proceso educativo, entre ellas se encuentra la necesidad de desarrollar un liderazgo transformacional que le permita orientar e influir en sus estudiantes adecuadamente para potenciar el interés hacia el aprendizaje y alcance de los objetivos personales y colectivos.

De este modo, el docente como líder transformacional y transaccional, de acuerdo con Mendoza, Ortiz y Parker (2017): es aquel que en "el liderazgo transaccional se refiere a la relación de intercambio entre el líder y sus seguidores con la finalidad de que sus intereses coincidan" (pág. 27). En este sentido debe promover el cambio más allá de los paradigmas establecidos, para lo cual es necesario generar ideas que sean del agrado de todos, 
fomentar la colaboración en el aula, incentivar la creatividad y mantener una visión de futuro, pero sobre todo debe motivar a sus estudiantes para que demuestren compromiso para con su proceso de aprendizaje.

Por consiguiente, el docente como líder transformacional debe tener la cualidad de comunicar, informar y orientar a sus estudiantes para que identifiquen y ponga en práctica los valores, promoviendo la comunicación, el respeto, la voluntad personal, y la interacción para el alcance de objetivos individuales y grupales.

\subsection{Discurso del docente como líder transformacional}

El discurso del docente se concibe como una herramienta pedagógica, pues a través del lenguaje se puede fomentar el desarrollo integral del educando, tal y como lo plantea Martínez-Otero (2007): cuando señala que puede "promover el desarrollo intelectual, emocional, moral y social del educando, según los objetivos que persiga" (pág. 3); por ello, la acción comunicativa que ejerce el docente a través de su discurso puede generar grandes transformaciones en la práctica pedagógica del aula.

En tal sentido, el discurso del docente como líder transformacional se concibe como la acción comunicativa que regula el proceso pedagógico a través de los actos ilocucionarios, locucionarios y perlocucionarios de habla, generando una intencionalidad transformadora, así como una reacción productiva en sus estudiantes hacia el alcance de nuevos conocimientos.

En este mismo orden de ideas, el discurso del docente como líder transformacional mantiene su acto locucionario (lo que dice) plagado de una pragmática motivadora, carismática, proactiva, creativa e interactiva enlazando los elementos esenciales del discurso con gran coherencia a fin de influir, inducir y animar a los estudiantes a transformar el aprendizaje partiendo siempre desde su connotación social. En consecuencia, y en atención con los planteamientos de Diazgranados y Pastrana (2017b): el docente a través de 
su discurso, debe tener la capacidad de: "aplicar las técnicas y orientaciones que conlleven al estudiante a un aprendizaje donde pueda dar testimonio sobre la capacidad de sacar o generar conclusiones" (pág. 27); es decir, transformar su propio aprendizaje, construir un nuevo conocimiento de manera auténtica, adjudicando un significado propio a su proceso educativo y estimulando la autorrealización.

Finalmente, a través del discurso del docente como líder transformacional se puede generar un vínculo emocional entre el docente y sus estudiantes, motivando el alcance de objetivos comunes y desarrollando la autoestima, la seguridad personal, la capacidad productiva originando una reacción positiva ante el proceso pedagógico, así como un mayor desempeño de los estudiantes.

\subsection{Particulares del discurso docente como líder transformacional}

El discurso docente como acto comunicativo, se ancla a los planteamientos de la teoría de los actos del habla, en tal sentido una de las principales particularidades del discurso del docente como líder transformacional se basa en los actos locucionarios, ilocucionarios y perlocucionarios del discurso, los cuales consisten en:

Acto locucionario: corresponde a lo que se dice, es decir, la emisión literal de las palabras, en tal sentido en el discurso del docente como líder transformacional estas palabras están caracterizadas por ser motivadoras, estimulantes, alicientes, atractivas, alentadoras. Frases como: se puede, podemos lograrlo, excelente, muy bien, demuestran como el docente, incentiva y ejerce influencia sobre sus estudiantes.

Acto ilocucionario: se refiere a la intencionalidad con la que se habla, el propósito que se desea alcanzar con el discurso, por consiguiente, el discurso del docente como líder transformacional debe mantener una fuerza intencional cargada de estímulo intelectual, motivación, carisma, inspiración, y 
reconocimiento individual, inspirando el alcance de objetivos tanto individuales como comunes, promoviendo la transformación del conocimiento e indicando la ruta hacia el éxito.

Acto perlocucionario: es el efecto o reacción que el acto ilocucionario produce en los estudiantes. En el discurso del docente como líder transformacional, este acto debe promover reacciones emocionales y sicológicas en los estudiantes, así como mejor desempeño académico permitiendo maximizar la eficacia y efectividad de los procesos de enseñanzaaprendizaje.

En definitiva, a través del discurso del docente como líder transformacional se logra que los estudiantes se sientan capaces de aprender de manera autorregulada, tomando sus propias decisiones cognoscitivas y aplicando las estrategias que considera más pertinente en su proceso de aprendizaje. Asimismo, permite establecer relaciones interpersonales eficaces y una comunicación efectiva entre los miembros del grupo, construyendo excelentes relaciones personales y permitiendo la fácil solución de conflictos.

Recíprocamente, el docente como líder transformacional a través de su discurso se muestra como guía y motivo de inspiración para sus estudiantes gracias a su personalidad entusiasta, carismática, proactiva, empática, innovadora, democrática, y optimista; en tal sentido, su discurso de manifiesta en dos dimensiones: la enseñanza y el aprendizaje.

De acuerdo a Diazgranados y Pastrana (2017c): la enseñanza, está orientada a instruir, "comprender y manejar aquellos procesos que de una $u$ otra forma contribuyen en la construcción de significados" (pág. 34). La segunda dimensión, el aprendizaje, está relacionada con la capacitación y la autorrealización, es decir, como señalan Diazgranados y Pastrana (2017d): "la aprehensión de los conocimientos, integrado al desarrollo de aquellas habilidades y capacidades de acción en el contexto donde ejecuta su tarea" 
(pág. 34). En definitiva, el discurso del docente como líder transformacional permite impulsar, facilitar y coordinar los procesos de transformación, pero para ello es necesario que el docente posea la capacitación adecuada y serio compromiso tanto con la educación como con la sociedad, permitiéndole ponerse a la cabeza del proceso de cambio.

\subsection{Elementos que caracterizan el discurso del docente como líder transformacional.}

El docente como líder transformacional a través de su discurso promueve relaciones definidas por la confianza y el respeto, aspectos que favorecen la praxis pedagógica tanto en lo individual como en lo colectivo, apoyando a los estudiantes en su crecimiento académico a través de un clima escolar armonioso y empático. Así mismo, a través del discurso el docente transformacional incita, estimula y motiva a sus estudiantes a tomar conciencia de la importancia que tiene el trabajo en equipo dentro del aula, desarrollando en los mismos, lo planteado por Omar (2011), citado por Lugo (2015), donde exponen: "el sentido de colaboración, participación, pertenencia y servicio, hacia la búsqueda de los objetivos institucionales en beneficio a la colectividad" (pág. 32).

Por consiguiente, a continuación, se mencionan los elementos fundamentales que caracterizan la teoría del discurso del docente como líder transformacional:

a). Estimulación: proporciona a los estudiantes las condiciones adecuadas para mejorar las oportunidades de desarrollo físico, intelectual y social, además incita a los mismos para que sus capacidades y habilidades le permitan ser mejor.

b). Motivación: impulsa el comportamiento de los estudiantes con el propósito de alcanzar los objetivos propuestos. 
c). Persuasión: destinado a modificar la actitud de los estudiantes hacia el aprendizaje y todo lo que el mismo compete. A través del mismo el docente guía a sus estudiantes hacia la adopción de una idea, o una actitud mediante significados racionales y simbólicos.

d). Connotación: utiliza frases con sentido agrupado, expresivo o adicional, a fin de adecuarse al contexto del estudiante y atribuirle un sentido social y real a su manifestación verbal.

e). Performativo: capacidad que tiene el docente para convertir sus expresiones verbales en acciones y transformar el contexto, enseñando con el ejemplo, de acuerdo a Diazgranados y Pastrana (2017e): "remite a la idea de que todo discurso tiene una dimensión social, en la que al producir un acto de habla se cumplen condiciones de adecuación, intenciones, conocimientos y opiniones insertas en el contexto del hablante" (pág. 26); y que pueden ser representadas.

f). Asertivo: capacidad que tiene el docente como líder transformacional para expresar adecuadamente sus opiniones, deseos y sentimientos en su discurso. De este modo, según Giraldo, Rubio y Fernández (2009): "el docente mediante los actos de habla asertivos propone una tarea semi- definida, con la intencionalidad de obtener respuestas motrices creativas" (pág. 29).

g). Declarativo: a través del mismo el docente pretende representar situaciones posibles para sus estudiantes, incentivándolos para la transformación de los conocimientos y el alcance de resultados.

h). Orientador: de acuerdo a Meza y Flores (2014e): el discurso del docente como líder transformacional, tiene "la capacidad para orientar y apoyar el logro de metas de cada persona, haciéndolas agentes de su propia formación" (pág. 108).

i). Proactividad: crea acciones discursivas que generen un comportamiento anticipatorio y previsorio orientado al cambio o a la 
transformación del proceso de enseñanza.

j). Coherencia: capacidad de articular ordenadamente las ideas del discurso en un contexto y en momento determinado, procurando la armonía entre lo que piensa, dice y hace.

k). Flexibilidad: se adapta a las situaciones que se presentan, demostrando seguridad y originando confianza.

En tal sentido, el docente como líder transformacional debe utilizar su discurso para animar, entusiasmar y crear confianza en sus estudiantes para que persigan sus ideales educativos y construyan una visión de futuro con proyectos realizables y estrategias que le permitan alcanzar sus objetivos, para ello debe proveer una visión clara de los mismos. De igual modo debe estar dirigido a persuadir a los individuos, reconocer en los mismos sus necesidades individuales y atenderlas, con el propósito de guiarlos de acuerdo a sus capacidades y habilidades, para abrir oportunidades en el aprendizaje autorregulado, sin dejar de prestar orientación, como se puede observar en la tabla 1.

Tabla 1. Discurso del docente como líder transformacional.

\begin{tabular}{|l|l|}
\hline \multicolumn{1}{|c|}{ Elementos } & \multicolumn{1}{c|}{ Características } \\
\hline Acto locucionario. & Estimulante; Motivador; Persuasivo. \\
\hline Acto ilocucionario. & Connotativo; Performativo; Asertivo; Declarativo. \\
\hline Acto perlocucionario & Orientador; Proactivo; Coherente; Flexible. \\
\hline
\end{tabular}

Fuente: La Autora (2019).

\section{Referencias}

Arias, F. (2012). El proyecto de investigación: Introducción a la metodología científica. 6ta edición, ISBN: 980-07-8529-9. Caracas, Venezuela: Editorial Episteme, C.A.

Austin, J. (1982). Cómo hacer las cosas con palabras. Colección Básica, ISBN 10: 8475091415; ISBN 13: 978-8475091419. España: Ediciones 
Paidós, 224 págs.

Conger, J., \& Riggio, R. (2006). The Practice of Leadership: Developing the Next Generation of Leaders. ISBN: 978-0-787-98305-5, San Francisco, EE. UU.: Editorial Jossey-Bass, 432 págs.

Diazgranados, H, \& Pastrana, E. (2017a,b,c,d,e). Influencia del discurso docente en las actitudes violentas de los niños de grado tercero de la Institución Mercedes Ábrego de la ciudad de Montería. Bogotá, Colombia: Universidad Santo Tomás. Recuperado de: https://repository.usta.edu.co/bitstream/handle/11634/9322/PastranaEr ika2017.pdf?sequence $=1$ \&isAllowed $=y$

Giraldo, L., Rubio, E., \& Fernández, J. (2009). Caracterización del discurso pedagógico del docente de Educación Física e identificación de los actos de habla que estimulan la creatividad motriz. Agora para la educación física y el deporte, (11), 25-41, e-ISSN: 1578-2174. Recuperado de:

https://dialnet.unirioja.es/descarga/articulo/3116435.pdf

Lugo, B. (2015). Visión Holística del Gerente como Líder Transformador en el contexto educativo. Bárbula, Carabobo, Venezuela: Facultad de Ciencias de la Educación de la Universidad de Carabobo. Recuperado de: https://studylib.es/doc/1198651/blugo.pdf

López, C. (2019). El Liderazgo y la Axiología del Docente en la Educación Primaria. Revista Scientific, 4(12), 240-253, e-ISSN: 2542-2987. Recuperado de:

https://doi.org/10.29394/Scientific.issn.2542-2987.2019.4.12.12.240$\underline{253}$

Martínez-Otero, V. (2007). Modelo pedagógico del discurso educativo y su proyección en la calidad docente, discente e institucional. Revista Iberoamericana de Educación, 43(2), 1-11, e-ISSN: 16815653; ISSN 1022-6508. Recuperado de: 
https://rieoei.org/RIE/article/view/2334

Mendoza, I., Ortiz, M., Parker, H. (2017). Dos décadas de investigación y desarrollo en liderazgo transformacional. Revista del Centro de Investigación, 7(27), 25-41, e-ISSN: 1405-6690. Recuperado de:

https://www.redalyc.org/articulo.oa?id=34202702

Meza, M., \& Flores, I. (2014a,b,c,d,e). El liderazgo transformacional en el trabajo docente: Colegio Mier y Pesado, un estudio de caso. Revista Educación, 38(1), 101-115, e-ISSN: 2215-2644. Recuperado de: https://doi.org/10.15517/revedu.v38i1.14380

Morín, E. (1999). La cabeza bien puesta: repensar la reforma: reformar el pensamiento. ISBN: 978-950-602-395-9. Buenos Aires, Argentina: Ediciones Nueva Visión, 143 págs.

Omar, A. (2011). Liderazgo transformador y satisfacción laboral: El rol de la confianza en el supervisor. Liberabit. Revista de Psicología, 17(2), 129-137, e-ISSN: 1729-4827. Recuperado de:

http://www.redalyc.org/pdf/686/68622584003.pdf

Riggio, R., \& Reichard, R. (2008). The emotional and social intelligences of effective leadership: An emotional and social skill approach. Journal of Managerial Psychology, 23(2), 169-185, e-ISSN: 0268-3946 Recuperado de:

https://www.semanticscholar.org/paper/The-emotional-and-socialintelligences-of-effective-Riggio-

Reichard/3db13dc6c7e5d39f1147444f9f4212fd76366bd28

Sabino, C. (2007a,b). Los Caminos de la Ciencia: una introducción al método científico. Colección Lumen, ISBN: 978-987-00-0616-9. Argentina: Editorial Lumen.

Searle, J. (2017). Actos de habla: ensayo de filosofía del lenguaje. Colección Teorema: Serie mayor, ISBN 10: 8437636817; ISBN 13: 9788437636818. Madrid, España: Ediciones Cátedra, S.A., 245 págs. 
Urra, E., Muñoz, A., \& Peña, J. (2013). El análisis del discurso como perspectiva metodológica para investigadores de salud. Enfermería Universitaria, 10(2), 50-57, e-ISSN: 2395-8421. Recuperado de: http://www.scielo.org.mx/scielo.php?pid=S166570632013000200004\&script=sci abstract

Vázquez, S., Bernal, J., \& Liesa, M. (2014). La conceptualización del liderazgo: una aproximación desde la práctica educativa. REICE. Revista Iberoamericana sobre Calidad, Eficacia y Cambio en Educación, 12(5), 79-97, e-ISSN: 1696-4713. Recuperado de: http://www.redalyc.org/pdf/551/55132460004.pdf 


\section{Karen Tatiana Quintero Gutiérrez}

e-mail: tatica37@hotmail.com

Nacida en Mérida, Venezuela, el 31 de diciembre del año

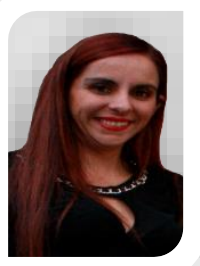
1978. Profesora en Educación Integral de la Universidad Pedagógica Experimental Libertador (UPEL); Postgrado en Planificación y Evaluación de la Educación en la Universidad Santa María (USM); Doctorando en Ciencias de la Educación de la UPEL; Docente de educación primaria; Docente de pregrado y postgrado en la UPEL. 